\title{
CLINICO-PATHOLOGICAL ANALYSIS OF MALIGNANT EYELID AND ADNEXAL TUMOURS PRESENTING TO A TERTIARY EYE HOSPITAL OF EASTERN NEPAL
}

\author{
Kafle $P A^{1^{*}}$, Hamal $D^{2}$, Sahu $S^{3}$, Poudyal $P^{4}$, Kafle $S U^{5}$
}

\section{Affiliation}

1. Consultant Ophthalmologist and Head-Oculoplasty Department, Biratnagar Eye Hospital, Biratnagar

2. Consultant Ophthalmologist and Oculoplastic surgeon -Biratnagar Eye Hospital, Biratnagar

3. Consultant Ophthalmologist and Oculoplastic surgeonSagarmatha Chaudhary Eye Hospital, Lahan

4. Consultant Pathologist, Department of Ophthalmic Pathology and Laboratory Medicine, Biratnagar Eye Hospital, Rani, Biratnagar

5. Associate professor and Head-Birat Medical College,Budhiganga-2, Tankisunuwari, Morang

\section{ARTICLE INFO}

Received : 31 October, 2019

Accepted : 23 December, 2019

Published : 31 December, 2019

(C) Authors retain copyright and grant the journal right of first publication with the work simultaneously licensed under Creative Commons Attribution License CC - BY 4.0 that allows others to share the work with an acknowledgment of the work's authorship and initial publication in this journal.

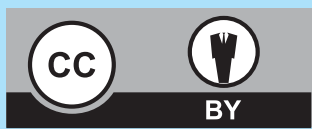

ORA 143

DOI: http://dx.doi.org/10.3126/bjhs.v4i3.27036

\section{* Corresponding Author}

Dr. Prerna Arjyal Kafle Consultant

Ophthalmologist and Head - Oculoplasty Department, Biratnagar Eye Hospital, Biratnagar

Email: arjyalprerna@gmail.com

ORCID ID: https://orcid.org/0000-0001-7181-7622

\section{Citation}

Kafle PA, Hamal D, Sahu S, Poudyal P, Kafle SU. Clinico-pathological Analysis of Malignant Eyelid qnd Adnexal Tumors Presenting to A Tertiary Eye Hospital of Eastern Nepal. BJHS 2019;4 (3)10:840-844.

\section{ABSTRACT}

\section{Introduction}

Eye lid and adnexal tumours are one of the major problems we see in the oculoplastic department. Malignant eye lid tumours are rare in comparison to benign and diversity in its clinical presentation makes it difficult to diagnose at early stage. Eyelid malignancies can mimic a host of benign neoplasms and other less aggressive neoplastic or nonneoplastic inflammatory conditions and need differentiation before definitive therapy is planned. Out of $90 \%$ of all skin cancer occurring in head and neck region $10 \%$ occurs in the eyelid. A histopathological study confirms the diagnosis that can be correlated with patient history and other clinical data.

\section{Objective}

To study the clinicopathological correlation and its outcome in patients with malignant eyelid and adnexal tumours presenting at Biratnagar eye hospital.

\section{Methodology}

Details of the cases of histopathologically proven malignant eyelid and adnexal tumours presenting to the department of oculoplasty from July 2016 to August 2019 were recorded. The duration of disease, presenting symptoms, risk factors, demographic data, clinicopathological correlation with its accuracy and mode of treatment were analyzed using SPSS 17.

\section{Result}

Out of total 28 patients, male were $53.6 \%$ and female were $46.4 \%$. The mean age of presentation was $60.5 \pm 11.8$ years. $53.6 \%$ tumors were located in upper lid, $39.9 \%$ were located in lower lid and $7.1 \%$ were located in medial canthus. Basal cell carcinoma and sebaceous gland carcinoma were the most common type of malignancies ( $35.7 \%$ each) followed by $28.6 \%$ of squamous cell carcinoma of eyelid. The clinicopathological correlation revealed $75 \%$ of clinical accuracy. Different types of reconstructions were done according to the size and site of the defect. Modified Hughes procedure for lower eyelid defect was the most common procedure performed (32.1\%), followed by $14.3 \%$ Cutler beard, $28.6 \%$ Cutler beard with post auricular cartilage graft, $10.7 \%$ Glabellar flap rotation $7.1 \%$ had combined procedure and $4.3 \%$ direct closure .

\section{Conclusion}

Sebaceous cell carcinoma and Basal cell carcinoma were the most common malignant tumors followed by squamous cell carcinoma. The upper lid was the most common site for such malignancy. Histopathological examination was useful for the establishment of complete and accurate diagnosis, which led to further management and follow up protocol for malignant eyelid tumours.

\section{KEYWORDS}

eyelid reconstructions, histopathological correlation, location, malignant eyelid tumours, 


\section{INTRODUCTION}

Eyelid and adnexal tumours are commonly encountered in ophthalmic practice and form an important part in ophthalmology practice. These tumours are significant cause of morbidity and mortality especially in developing countries like ours. Different varieties of tumor can occur at different tissue level. Out of $90 \%$ of all skin cancer occurring in head and neck region, $10 \%$ occurs in the eyelid. ${ }^{1}$ Malignant eyelid tumors are rare in comparison to benign tumors, but diversity in its clinical presentation makes it challenging to diagnose and treat early. Eyelid malignancies can mimic a host of benign neoplasms and other less aggressive neoplastic or non-neoplastic inflammatory conditions and need differentiation before definitive therapy is planned. ${ }^{2}$ Also, different types of malignant eyelid tumors may have similar gross appearance but their clinical course, outcome and prognosis may be different. Although most of the eyelid tumors are diagnosed clinically, histopathological examinations give us the final diagnosis which can be correlated with the clinical picture. This helps us to plan further management, know the prognosis of the disease and thus provides great benefit to ongoing patient care. ${ }^{3}$

The main malignant tumors affecting the eyelid are basal cell carcinoma (BCC), sebaceous gland carcinoma (SGC), squamous cell carcinoma (SCC), and malignant melanoma (MM). Basal cell carcinoma (BCC) is the most common malignant eyelid tumor and accounts for $80-95 \%$ of all eyelid malignancies in Western countries. ${ }^{4,5}$ Sebaceous gland carcinoma occur less frequently in west than in Asian countries. ${ }^{6-11}$ There are thus global variations in the type of eyelid and adnexal tumors according to the geographic location and ethnicity.

There are limited studies from Nepal related to tumors of eyelid and adnexa with their clinicopathological correlation. This study was done to analyze the demography, identify the clinical presentation of different malignant eyelid and adnexal tumors, gross and histopathological diagnosis and its clinico-pathological correlation with the clinical diagnosis that makes it more helpful for further management of the patients.

\section{METHODOLOGY}

This is a hospital based, cross sectional, descriptive study which included data of all the consecutive cases of malignant eyelid tumors presenting to the Department of Oculoplasty of Biratnagar Eye Hospital between July 2016 to August 2019 and who underwent surgical excision with histopathology examination. The ethical approval was taken from institutional review committee and the study adheres to the declaration of Helsinki.

Inclusion criteria: All consecutive patients with eyelid and adnexal tumours who were surgically treated and had malignant tumour as histopathological diagnosis were included in the study.

Exclusion criteria: Patients who did not give consent for the study, those who had inflammatory, infective or benign lesion in histopathology examination and those cases which did not have histopathology reports were excluded from the study.

The data extracted were: age, sex, laterality, tumor location and its extent, duration of the disease, presenting symptoms, risk factors like tobacco chewing, clinical diagnosis, lymph nodes involvement at the time of presentation, preoperative and postoperative clinical photographs to ensure the clinical diagnosis. Recorded surgical procedure included excision of the mass with $4-5 \mathrm{~mm}$ clear margin followed by different types of reconstructions like direct closure, modified Hughes, cutler beard or any of the needed combined flaps and grafts depending upon the size of defect following the tumour excision. All specimens were sent for histopathological examination with sutures placed in the specimen to label its orientation for seeing the involvement of margin and extent of tumour pathology. Histopathology reports were retrieved and clinicopathological correlation with its accuracy was noted. All the data were analyzed using SPSS 17 , chi square test were used for categorical data.

\section{RESULTS}

A total of 28 patients with a histopathology proven eyelid and adnexal malignancy were included in this study. The mean age of presentation was $60.5 \pm 11.8$ years (range from 32 years to 81 years). Among them $53.6 \%$ were male and $46.4 \%$ were female. According to the types of malignancy, male had more number of squamous cell carcinoma and female had equal number of basal cell carcinoma and sebaceous gland carcinoma [Table 1]. Left eye was predominantly affected (53.6\%).

\begin{tabular}{|c|c|c|c|c|}
\hline TYPE & NUMBER & $\%$ & MALE & FEMALE \\
\hline BCC & 10 & 36.7 & 4 & 6 \\
\hline SGC & 10 & 35.7 & 4 & 6 \\
\hline SCC & 8 & 28.6 & 7 & 1 \\
\hline TOTAL & 28 & 100 & 15 & 13 \\
\hline
\end{tabular}

Regarding the site of the tumor, upper lid was most commonly involved (53.6 \%) followed by lower lid and medial canthus area in $39.9 \%$ and $7.1 \%$ respectively. Among the patient who had upper lid malignancy, $60 \%$ had more than $2 / 3^{\text {rd }}$ of upper lid involved, $26.7 \%$ had involvement in lateral part and $13.3 \%$ had involvement in medial part. Similarly, lower lid malignancy was seen in medial part in $45.5 \%$ and in lateral part in $45.5 \%$.

Mean time lapse between appearance of symptoms and presentation at hospital was $25 \pm 29.47$ months. Due to late presentation in most of the cases, the presenting signs also varied. However, $53.6 \%$ had only mass and $28.6 \%$ had ulcerated mass at the time of presentation [Table 2]. Out of 
total 28 cases, $25.3 \%$ had palpable regional lymph nodes at the time of presentation. Considering tobacco as one of the commonest risk factor of malignancies, $39.3 \%$ were active smokers and $10.7 \%$ were tobacco chewers.

\begin{tabular}{lc}
$\begin{array}{l}\text { Table 2: Clinical features at the time of presentation } \\
\text { Presenting features }\end{array}$ & Frequency (\%) \\
\hline Mass & $53.6 \%$ \\
Ulcerated wound & $28.6 \%$ \\
Mechanical ptosis & $7.1 \%$ \\
Orbital extension & $7.1 \%$ \\
Mechanical ectropion & $3.6 \%$ \\
Total & $100 \%$ \\
\hline
\end{tabular}

Out of 28 cases, 10 cases each (35.7\%) were diagnosed as Sebaceous gland carcinoma (SGC) and Basal cell carcinoma (BCC) and 8 cases (28.6\%) were diagnosed as Squamous cell carcinoma (SCC) after the histopathology examination. Among them in BCC, lower lid was the most common site of involvement (6 cases) followed by upper lid and medial canthus (2 cases in each). Likewise upper lid was mostly involved in SGC (7 cases) than lower lid (3 cases). And SCC was more commonly found in upper lid (6 cases) than in lower lid ( 2 cases). $75 \%$ accuracy was seen while correlating the clinical and histopathological diagnosis in all cases [Figure1]. $67.9 \%$ of cases had margin positive for malignancy on histopathology examinations. Among them 2 cases had palpable lymph nodes.

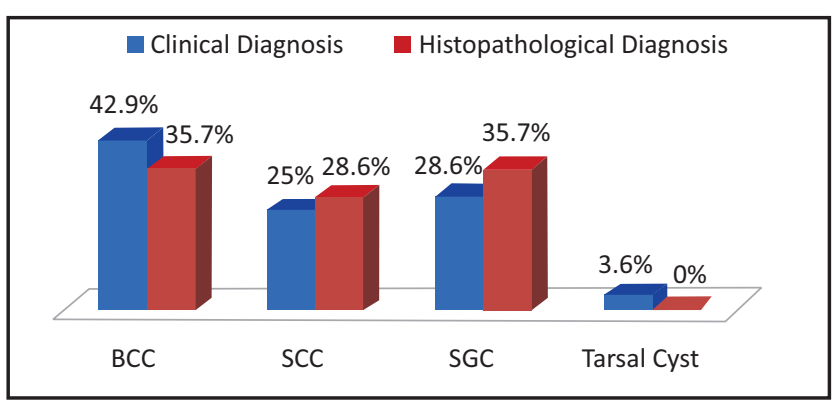

Figure 1: Clinicopathological correlation of different eyelid malignancies
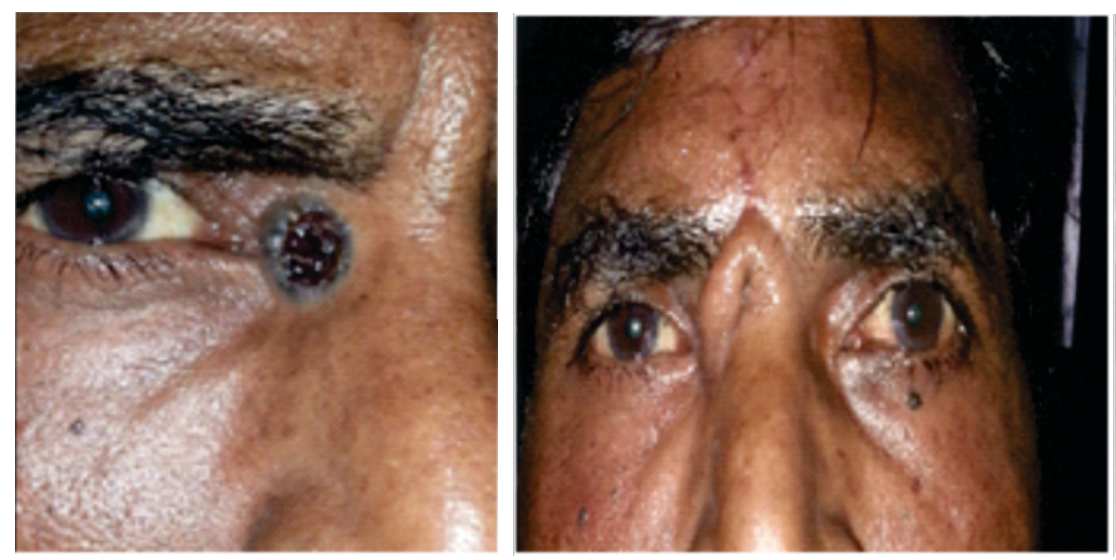

All the cases underwent complete mass excision with 4-5 $\mathrm{mm}$ surrounding clear margin and reconstruction at the same time. Different types of reconstructions were done according to the size and site of the defect [Figure 2]. Modified Hughes's procedure for lower eyelid defect was the most common procedure performed (32.1\%).

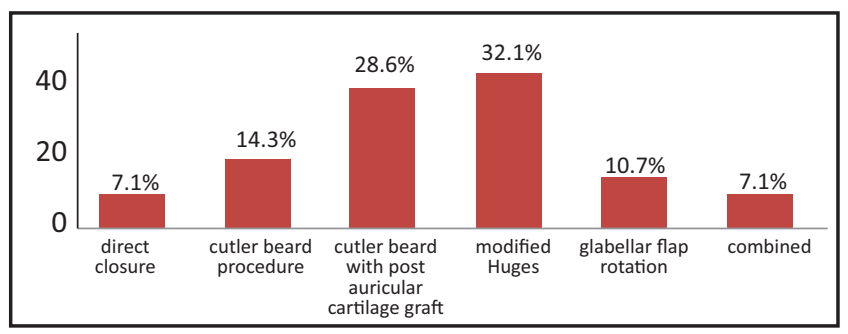

Figure 2: different types of reconstructions after tumour excision

Only 3 patients ( $10.7 \%$ ) had more than 1 year follow-up, 5 patients (17.9\%) had 6 months and 3 months follow up in each group. At least 6 weeks of follow-up was seen in most of the cases (10/28, 35.7\%). (Picture: 1, 2 and 3). 3 patients did not come for follow up after the initial surgery. Out of the total 28 patients operated, 3 had recurrence (2 SGC and $1 \mathrm{BCC}$ ) and among them $\mathrm{BCC}$ had recurrence in 3 month, SCC and SGC and in 3months and 6 weeks respectively. All of them had margin involvement in histopathological examinations. One of the SGC case had lymph nodes involvement too. All of them were referred to oncology center for further management.

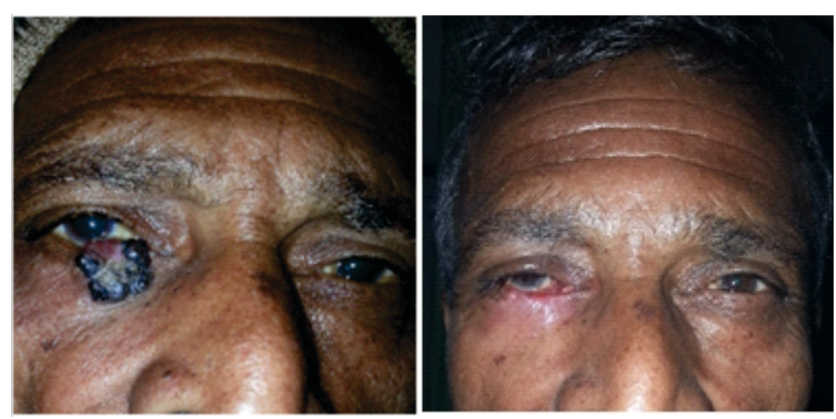

Picture .1: showing preoperative and post-operative (after 6 weeks) photographs of right lower lid BCC following modified Hughes procedure.

Picture.2: showing preoperative and post-operative ( 6 weeks and 1 year) photographs of right medial canthal BCC following glabellar flap rotation flap 


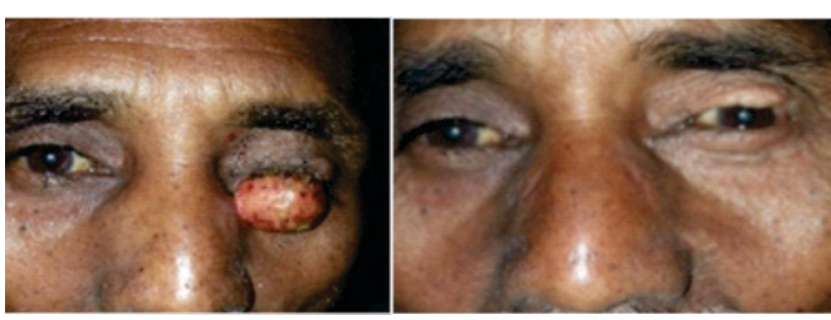

Picture.3: showing preoperative and post-operative( 1 year) photographs of left upper lid sebaceous gland carcinoma following cutler beard procedure with autologous postauricularcartilage graft

\section{DISCUSSION}

Various studies have been done regarding eyelid and adnexal tumors in different part of the world. These tumours may show geographical and ethnic variation. The data of our study shows the demography, various modes of presentations and ethnic variation of the malignant eyelid tumours presenting in a tertiary eye care centre in the eastern part of Nepal. This data will serve as a reference for this geographical region and guide in planning resources for screening as well as in proper management of the eyelid tumours. It will also be useful in assessing the requirements of oculoplasty set up of the hospital and will help in future eye health care provisions.

The mean age of presentation was $60.5 \pm 11.8$ years ( 32 years to 81 years ) in this study, which is similar with other studies done by Gautam P et al ${ }^{10}$,Kaliki S. et.al ${ }^{12}$ and I. Hussain et.al ${ }^{13}$ where mean age of presentation was $>50$ years. This shows that eyelid malignancies are more commonly seen in older age group. In our study, male predominance is seen (male $53.6 \%$ vs female $46.4 \%$ ), in contrast to other studies done by Wang CJ et.al ${ }^{14}$, Karan S et al ${ }^{15}$, Gosai et $\mathrm{al}^{16}$, where female were reported to be more affected. Pombejara et al $^{17}$ reported that male was more commonly affected similar to our study.

The mean time lapse between appearance of symptoms and presentation at hospital was $25 \pm 29.47$ months in this study. The corresponding time in an Indian study was 7.2 months for $\mathrm{SGC}^{18}, 13.5$ months in a Turkish study ${ }^{19}$ and 37.8 months in a study from Pakistan. ${ }^{13}$ The delayed presentation may be due to distance of hospital, lack of awareness and selfneglect in old age and socio-economic problems.

In our experience, BCC and SGC was the most common tumor (35.7 \% each) followed by SCC (28.6\%). In another study from Nepal, BCC was the commonest eyelid tumor (59.4\%) followed by SCC (15.6\%) and melanoma in $15.6 \%{ }^{20}$ A study from Singapore reported the frequency of different eyelid cancers over a 27 -year period as follows: BCC $84 \%$, SGC $10.2 \%$, SCC $3.4 \%$ and MM $1.2 \%$. $^{21}$ Similar study from India over a 34-year period showed BCC was commonest (38.8\%) followed by SGC in $27.1 \%$, SCC in $22.4 \%$ and MM in $3.5 \% .{ }^{22}$ In a study done in Central India by Jahagirdar et al where a series of 27 cases of eyelid malignancies were analyzed, sebaceous cell carcinoma (37\%) was almost as prevalent as basal cell carcinoma. ${ }^{18}$ Studies from Pakistan show BCC was commonest eyelid tumor (59\%) followed by
SCC (31.5 \%) and SGC (6.8 \%) in north-west Pakistan ${ }^{13}$ while in southern Pakistan, BCC (56.32\%) was commonest, tumor followed by SCC (20.69 \%) and SGC (14.94\%). ${ }^{23}$ Cumulative results of 26 studies from Japan (1976-2004) mentioned BCC to be $39.5 \%$, SCC $21.8 \%$, SGC $27 \%$. ${ }^{24}$ Thus, there are geographical variations in tumour frequency. In our study we could see that BCC and SCC were mostly present in lower lid (60\% and $75 \%$ respectively) and SGC was mostly present in the upper lid (70\%). Various studies have shown the predominance of BCC in the lower eyelid. ${ }^{25,26}$ Upper lid the most commonest site for periocular SGC, accounting for half to two thirds of cases due to a predominance of meibomian glands in the upper eyelid. ${ }^{3}$ No case of melanoma was seen in this study.When we see gender predilection of these tumours, our study shows that SCC is more common in male than in female ( 7 cases and 1 case respectively). Whereas a study done by Kaliki S. et.al showed slight female predilection with a male: female ratio of $1: 1.1 .^{12} \mathrm{BCC}$ and SGC were more common in female in our study. This is similar to the study done by Kaliki S. et.al. ${ }^{12}$ In this study $75 \%$ of total cases had clinical and histopathological correlation, which is statistically significant( $p$ value-<.001).

In this study $67.9 \%$ of cases had margin positive for malignancy on histopathology examinations. This is mainly due to large size and extent of tumour which made it difficulty in total excision of tumour with clear surrounding margins.

Recurrence was seen in 3 cases (10.7\%) in our study, in one case of BCC and two cases of SGC. Kale et al ${ }^{1}$ reported $1.90 \%$ of recurrence and Bagheri et al $^{27}$ reported $19 \%$ of $\mathrm{BCC}$ recurrence. None of the patients had any postoperative complications. Although most of the malignant eyelid tumors have favorable outcome in our experience, early diagnosis and intervention remains a corner stone for adequate functional and cosmetic lid reconstruction.

\section{CONCLUSION}

Basal cell carcinoma and sebaceous gland carcinoma is commonest malignant eyelid tumour in the older population. Most of the malignant lesions were confined to the eyelid only. Due to delay in presentation, the size and extent of tumour involvement varies. This leads to difficulty in total excision of tumour with clear surrounding margins. Reconstruction of bigger defects after the large tumour excision becomes more challenging. Timely diagnosis, management and proper follow-up are essential to reduce associated mortality and morbidity.

\section{RECOMMENDATION}

Every eyelid tumours should be treated with proper clinical examination, complete surgical excision and histopathological examination to reduce patient's morbidity in subsequent follow up. In the setup where patient follow up is poor more than $5 \mathrm{~mm}$ of clear margins should be taken to ensure free margin in histopathological examinations.Larger studies with longer follow-up should be conducted to identify the accurate clinicopathological features and prognosis of malignant eyelid tumors for further management. 


\section{LIMITATION OF THE STUDY}

There are few limitations of this study like the study being retrospective study, small sample size and short follow-up. Due to various reasons there are poor follow up of patients.

\section{ACKNOWLEDGEMENT}

Oculoplasty Department, Biratnagar eye hospital and Prof. Dr. Sanjay Kumar Singh for the continuous support.

\section{CONFLICT OFINTEREST}

None

\section{FINANCIAL DISCLOSURE}

None

\section{REFERENCES}

1. Kale SM, Patil SB, Khare N, Math M, Jain A, Jaiswal S Clinicopathological analysis of eyelid malignancies-a review of 85 cases. Indian J PlastSurg 2012; 45:22-28.

2. Rai NN. Introduction to ophthalmic cytology-modalities and classification of neoplasms. Journal of Cytology. 2007 Jan 1;24(1):11.

3. Font RL, Croxatto JO, Rao NA, editors. Tumors of the eyelids. In: Tumors of the Eye and Ocular Adnexa. Washington: American Registry of Pathology, AFIP; 2006. p. 155-221.

4. Tesluk GC. Eyelid lesions: incidence and comparison of benign and malignant lesions. 1985;17(11):704-707

5. Margo CE, Waltz K. Basal cell carcinoma of the eyelid and periocular skin. 1993;38(2):169-192

6. Ni C, Searl SS, Kuo PK, Chu FR, Chong CS, Albert DM. Sebaceous cell carcinomas of the ocular adnexa. 1982;22(1):23-61

7. Rajendra Kumar et.al Pattern of Ocular Malignant Tumors in Bhairahwa, Nepal .The Internet Journal of Ophthalmology and Visual Science 2009: Volume 7 Number 1

8. Ni Z. Histopathological classification of 3,510 cases with eyelid tumor [Zhonghuayankezazhi] Chinese journal of ophthalmology. 1996 Nov;32(6):435-7.

9. Gautam P, Adhikari RK, Sharma BR. A profile of eye-lid conditions requiring reconstruction among the patients attending an oculoplasty clinic in Mid-Western region of Nepal. Nepalese Journal of Ophthalmology. 2011;3(1):49-51

10. Gupta P, Gupta RC, Khan L. Profile of eyelid malignancy in a Tertiary Health Care Center in North India. J Can Res Ther 2017;13:484-6.

11. Lavaju P, Arya S K, Sinha A, Pandey S, Adhikari S, Shrestha B G, et al. Pattern of ocular tumours in the eastern region of Nepal. Nep J Oph 2009; 1: 9-12.

12. Kaliki S. et.al Malignant Eyelid Tumors in India: A Study of 536 Asian Indian Patients. OculOncolPathol 2019;5:210-219

13. Hussain I, Khan FM, Alam M, Khan BS. Clinicopathological analysis of malignant eyelid tumours in north-west Pakistan. J Pak Med Assoc. 2013 Jan $1 ; 63(1): 25-7$

14. Wang CJ, Zhang HN, Wu H, Shi X, Xie JJ, He JJ, KooK KH, Lee SY, Ye J. Clinicopathologic features and prognostic factors of malignant eyelid tumors. Int Journal of Ophthalmol 2013;6(4):442-447
15. Siddharth Karan, ManishaNathani, Tanveer Khan, suchetasen, aftabkhader. Clinicopathological study of eyelid tumours in Hyderabad-A review of 57 cases. J Med Allied Sci 2016;6(2)

16. Gosai J, Mehta D, Pherwani K, Bhatt R, Agrawal K, Tandel D. Clinical study of lid tumors in adults patients in western region of India. Journal of Evolution of Medical and Dental Sciences 2014; 3(73):15364-15373.

17. Pombejara FN, Tulvatana W, Pungpapong K. Malignant tumors of the eye and ocular adnexa in Thailand: a six-year review at King Chulalongkorn Memorial Hospital. Asian Biomed 2009; 3:551-555.

18. Jahagirdar SS, Thakre PT, Kale MS, Kulkarni H, Mamtani M. A clinicopathological study of eyelid malignancies from central India. Indian J Ophthalmol 2007; 55: 109-12.

19. Soysal GH, Markoc F. Invasive squamous cell carcinoma of the eyelids and periorbital region. Br J Ophthalmol 2007; 91:325-9.

20. Thakur SK, Sah SP, Lakhey M, Badhu BP. Primary malignant tumours of eye and adnexa in Eastern Nepal: Clinical Research. Clinical \& experimental ophthalmology. 2003 Oct;31(5):415-7.

21. Lee SB, Saw SM, Au Eong KG, Chan TK, Lee HP. Incidence of eyelid cancers in Singapore from 1968 to 1995 . Br J Ophthalmol 1999; 83: 595-7.

22. Abdi UN, Tyagi V, Maheshwari V, Gogi R, Tyagi SP. Tumours of eyelid: A clinicopathologic study. J Indian Med Assoc 1996; 94: 405-9

23. Farhat F, Jamal Q, Saeed M, Ghaffar Z. Evaluation of Eyelid Lesions at a Tertiary Care Hospital, Jinnah Postgraduate Medical Centre (JPMC), Karachi. Pak J Ophthalmol 2010; 26: 83-6.

24. Takamura H, Yamashita H. Clinicopathological Analysis of Malignant Eyelid Tumor Cases at Yamagata University Hospital: Statistical Comparison of Tumor Incidence in Japan and in other Countries. Jpn J Ophthalmol 2005; 49: 349-54.

25. Vaziri M, Buffam FV, Martinka M, Oryschak A, Dhaliwal H, White VA.Clinicopathologic features and behavior of cutaneous eyelid melanoma.Ophthalmology 2002;109(5):901-908

26. Mamalis N, White GL Jr, Pedersen DM, Holds J, Anderson RL. Malignant lesions of the eyelid. Am.Fam Physician 1989;39(1):95-102

27. Bagheri A, Tavakoli M, Kanaani A, Zavareh RB, Esfandiari H, Aletaha M, Salour H Eyelid masses: a 10-year survey from a tertiary eye hospital in Tehran. Middle East Afr J Ophthalmol 2013; 20:187-92. 